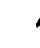
See pp 280 and 295
$-E D$

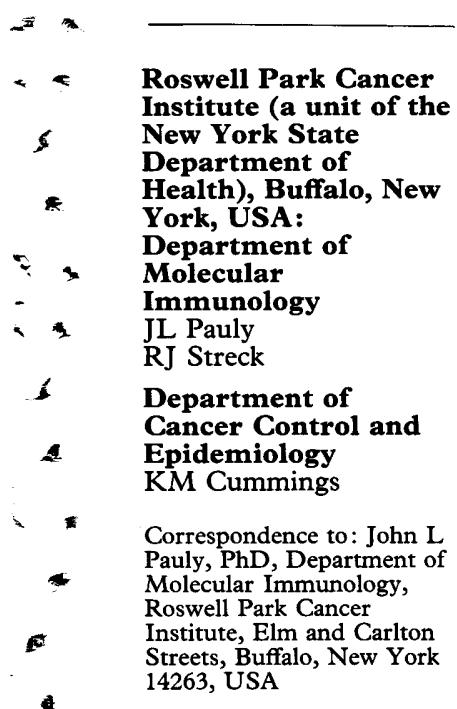

\title{
US patents shed light on Eclipse and future cigarettes
}

\author{
John L Pauly, Richard J Streck, and K Michael Cummings
}

\begin{abstract}
Objective - To define the anatomy of the Eclipse cigarette, and to compare the features of this smoking article with past and future low-smoke prototypes that heat instead of burn tobacco.

Design-A comparative analysis of Eclipse and Premier cigarettes was undertaken. This evaluation, and descriptions of smoking articles that have recently been awarded US patents, were used to identify emerging health, policy, and legal questions.
\end{abstract}

Results-In November 1994, the RJ Reynolds Tobacco Company (RJR) had been test marketing a low-smoke, cigarette-like, smoking article named Eclipse in at least eight different cities. Eclipse shares many of the features of Premier, which was introduced by RJR in 1988 and withdrawn from the market in 1990. Eclipse and Premier heat, but do not burn, the tobacco. These high technology smoking articles deliver nicotine to the user in vapour. Because the tobacco is not burned, there is reduced sidestream smoke and tar. It is not known (1) whether these new products will be able to satisfy consumers and create a market for individuals who wish to switch from conventional cigarettes; (2) what risks may be associated with their use; (3) who will test the products to ensure that the consumer is fully informed of the potential health risks.

Conclusions - The tobacco industry has spent much time, money, and effort to research and develop new smoking articles. Major changes in cigarette design have been introduced to achieve a reduction in smoke and in harmful agents generated during pyrolysis, while retaining the nicotine and flavour sought by the smoker. In these prototypes, the tobacco is not burned, an essential element in the definition of a cigarette. Accordingly, legal and regulatory policies are being challenged by those who have argued that a cigarette form has been selected for a device intended to deliver nicotine in a tobacco flavoured vapour.

(Tobacco Control 1995; 4: 261-265)

Keywords: US patents; low-smoke "cigarettes"; smoking article; nicotine; tobacco flavoured aerosol
Introduction

The RJ Reynolds Tobacco Company (RJR) recently introduced a low-smoke cigarette-like article named Eclipse to test panels, consisting of paid adult smokers, in at least eight different American cities (Atlanta, Buffalo, Chattanooga, Chicago, Cincinnati, Dallas, Detroit, and St Louis). The principal feature of Eclipse is that, unlike all other cigarettes currently marketed, the tobacco is heated and not burned.

The reasons why Eclipse was developed has not been disclosed by RJR; however, current wisdom would suggest that this cigarette was designed (1) to circumvent the increasing amount of legislation banning smoking in public buildings, restaurants, aeroplanes, sports stadiums, and other areas; (2) to extinguish mounting health concerns about secondhand smoke and offensive odour; (3) to reduce the pyrolysis of tobacco, which generates numerous combustion products including cancer-causing chemicals and toxic agents; and (4) to reverse falling cigarette sales in the United States. Various issues related to this $\$ 500$ million venture by RJR have been discussed in the media. ${ }^{1-3}$

Presented herein is a description of the anatomy of the multiple component Eclipse. This smoking article delivers to the smoker a nicotine enriched and tobacco flavoured aerosol under conditions that eliminate most of the smoke, odour, stain, and ash of conventional cigarettes.

\section{Methods}

In this overview, we have used information presented in US patents that have been assigned to RJR and other tobacco companies for low-smoke cigarettes, cigarette substitutes, and related prototypes. ${ }^{4-12}$ For more information, the reader should consult the myriad of US and foreign patents, as well as other references cited in the 1994 patents. $^{8-12}$ Also informative is the literature on the Premier cigarette, a predecessor of the Eclipse cigarette. This includes reports in a tobacco trade magazine ${ }^{13}$ a clinical pharmacology journal ${ }^{14}$ and a 744 page RJR monograph..$^{15}$ The monograph addresses chemical and biological studies on the "NEW CIGARETTE" (that is, Premier) and other cigarette prototypes that heat instead of burn tobacco. RJR has been providing a complimentary copy of their 
monograph to interested scientists and organisations.

\section{Results}

Many US and foreign patents have been awarded for smoking articles that produce an aerosol or vapour for inhalation. An extensive listing of these patents is presented in $^{\mathbf{1 0}}$; also see $^{4-9,11}$.

A patent for a cigarette having a carbon fuel element providing the heat source for vaporising nicotine, the essential feature of the Eclipse cigarette, was described in a US patent awarded 36 years ago. ${ }^{4}$ Despite the continued widespread interest and substantial financial commitment to developing the nicotine delivery devices that mimic cigarettes, none of them has been commercially successful. ${ }^{1,2,10}$

Eclipse is a smoking article, presented in a cigarette-like form, that produces a nicotine containing aerosol. The aerosol contains reduced amounts of incomplete combustion and pyrolysis products compared to those produced by a conventional cigarette. The smoke of a conventional cigarette consists of $\sim 80 \%$ tar and related particulate materials, and $\sim 20 \%$ water, glycerol, and nicotine. In contrast, Eclipse smoke is $\sim 15 \%$ tar, and $\sim 85 \%$ water, glycerol, and nicotine. ${ }^{1}$ Moreover, RJR claims that Eclipse eliminates $85-90 \%$ of the secondhand smoke. ${ }^{1}$

Repetitive attempts have been made to market variations of the conventional cigarette. For example, during the last 85 years, and most notably during tobacco rationed times of World War I and World War II, tobacco substitutes have been made of a variety of treated and untreated plant materials. ${ }^{15,16}$ These included beech leaves, dried blackberries, fermented tusilago leaves, Jerusalem artichoke, and chestnut leaves. ${ }^{15}$ Other materials that have been used or proposed include cocoa bean hulls, corn stalks, corn silk, eucalyptus leaves, lettuce leaves, sunflower leaves, rhubarb leaves, as well as products derived from wood and paper. ${ }^{10,15-17}$ None of these tobacco substitutes, however, has proved to be commercially successful. It is likely that the lack of commercial success attributed to the tobacco substitute products was due, at least in part, to the lack of nicotine-the addictive chemical.

The aerosols or vapours of many different tobacco substitutes have been tested and none has been found to fulfil the smoker's nicotine requirement. In essence, these countless and repetitive endeavours have failed to establish a market for non-tobacco smoking material. Clearly, nicotine will continue to be a central facet in conventional as well as new smoking articles.

The development of various devices for generating tobacco flavoured aerosols has also been well defined in different patents. Some proposed aerosol generating smoking articles have used a heat or fuel source in order to produce a tobacco flavored aerosol. The Premier cigarette ${ }^{13-15}$ was introduced by RJR on 1 October 1988 and was withdrawn from the test markets on 4 April 1990.

The failure of this aerosol generating nicotine delivery device was caused by various factors. A partial listing includes poor tobacco taste, off-taste due to thermal degradation of the smoke former and flavour agents, offensive odour, hot gases that were inhaled, and unsightly appearance. The Premier cigarette encountered strong opposition by major public health and medical groups, which influenced public perceptions about the product and the manufacturer's unproven health claims.

A comparison of the Premier and Eclipse cigarette is presented in the table. Eclipse is but one of a series of prototypes of NEW CIGARETTES (that is, Premier ${ }^{15}$ ) that heat instead of burn tobacco. A question arises as to the validity of designating these articles cigarettes. A cigarette has been defined in a 1993 US patent ${ }^{18}$ as a "charge or roll of smokable material (for example, tobacco cut filler) circumscribed by at least one layer of paper wrapping material to form a tobacco rod." Popular dictionaries offer similar descriptions. The term "smokable" and the phrase "for smoking" are essential terms in the definition. This nomenclature emphasises the fact that the tobacco is for burning, and that an aerosol is generated by tobacco combustion. By design and by performance, the tobacco in Premier ${ }^{15}$ and Eclipse is not burned and the aerosol is not generated by tobacco combustion.

Likewise, US patents, filed under the designation of "smoking articles," have been awarded for low-smoke products that are intended by the inventors to be used as cigarette-like items. However, these differ significantly from cigarettes that are marketed currently and which are sold, distributed, and smoked under the authority of existing regulations. Consequently, there exists a need to address legal, health, and policy issues related

Comparison of Premier and Eclipse cigarettes

\begin{tabular}{|c|c|c|c|}
\hline & Feature & Premier & Eclipse \\
\hline 1 & Heats, but does not burn, tobacco & Yes & Yes \\
\hline 2 & Carbon fuel source ${ }^{a}$ & Yes & Yes \\
\hline 3 & Glass fibres around insulator & Yes & Yes \\
\hline 4 & Filter & Polypropylene & Cellulose acetate \\
\hline 5 & Aluminium capsule & Yes & No \\
\hline 6 & Alumina beads & Yes & No \\
\hline 7 & Tobacco paper plug & Yes & No \\
\hline 8 & Regular and menthol flavour & Yes & Yes \\
\hline 9 & Tobacco columns & No & Yes (two) \\
\hline 10 & Tobacco sheet around insulator & No & Yes \\
\hline 11 & Manufacturing expense & Very high & High \\
\hline 12 & Currently available to consumers & No & No \\
\hline
\end{tabular}

Different designs used for Premier and Eclipse. 


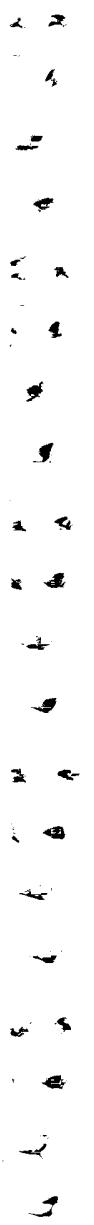

2

$\div$

c

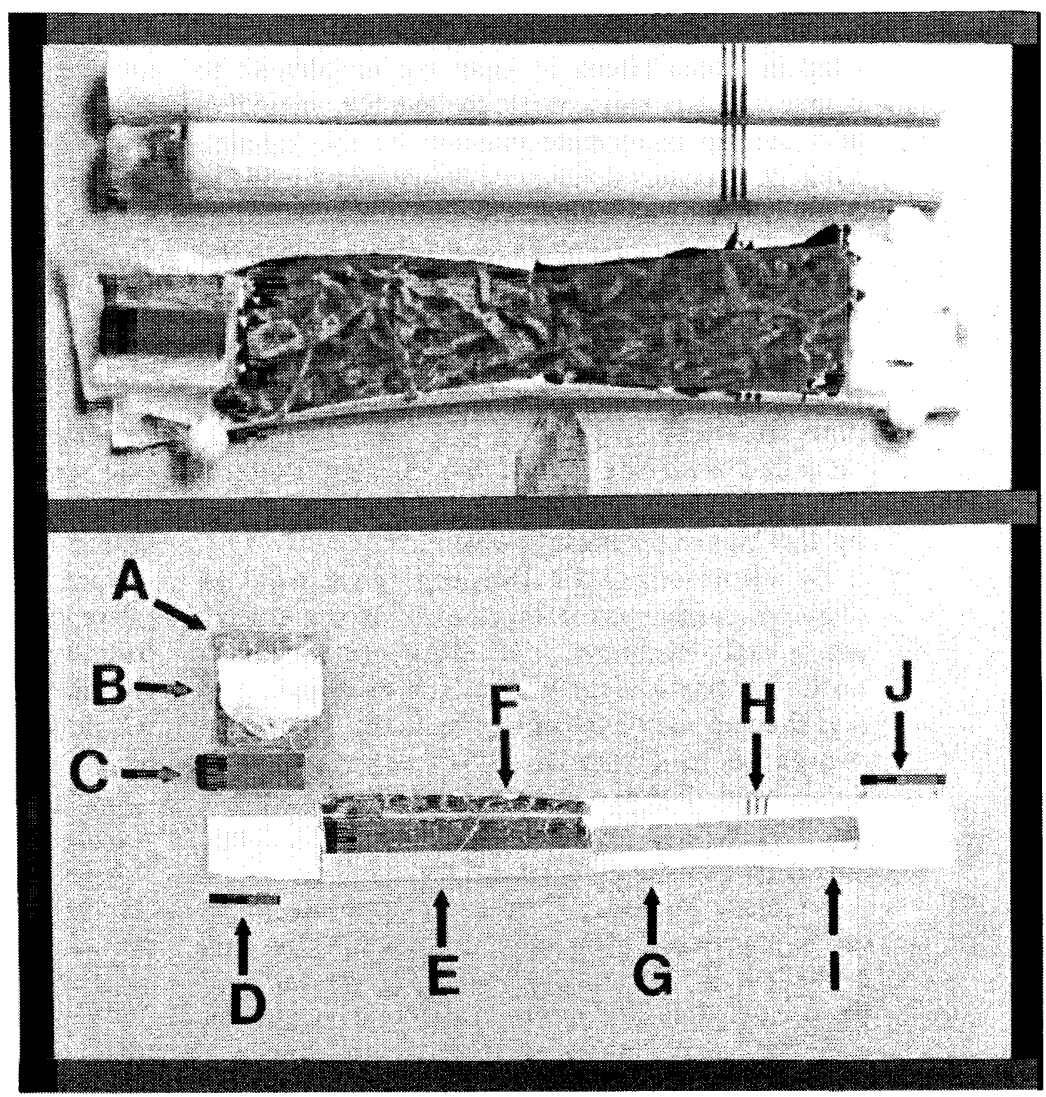

The anatomy of Eclipse (see text).

to these new smoking items that have been marketed as cigarettes.

The physical dimensions of the Eclipse cigarette closely approximate those of the conventional filter cigarette. With the exception of its overall appearance, all other traits of the Eclipse cigarette differ remarkably with other cigarettes that are marketed currently.

The anatomy of the Eclipse is presented in the figure. The upper panel illustrates an Eclipse cigarette before it had been ignited (top cigarette) and after being "smoked" completely (middle cigarette; note that the ashes are present on the tip only and that they remained attached). Also shown is an Eclipse cigarette that had been opened by cutting it longitudinally (bottom cigarette).

The lower panel is a view of a non-smoked Eclipse cigarette that had been dissected and the tobacco removed so as to illustrate the different components. The first segment (region $\mathrm{D}, \sim 12 \mathrm{~mm}$ long), readily apparent in the middle cigarette, houses the fuel element. The fuel element consists of a rod $(\sim 2 \mathrm{~mm} \times 12 \mathrm{~mm}$ ) of activated carbon (item C) that serves as the high temperature heat source for generating the aerosol. The carbon rod has five shallow, longitudinal grooves and a thin central channel. This design of the carbon rod facilitates heating the air that passes over its hot surface as one inhales each puff during the customary smoking process. The heat from this fuel source is approximately $900^{\circ} \mathrm{C}$; this temperature approximates the fire cone of a conventional cigarette. ${ }^{15,19}$

The fire element is wrapped in an insulating mantel of glass fibres (item B) which is designed to prevent igniting the tobacco in the adjacent segment.

The glass fibres are wrapped in a tobaccobrown overlay (item A). This overlay is thought to be "tobacco paper", which is a softwood kraft paper containing a tobacco extract. ${ }^{15}$ This segment also contains a unique paper which displays "desirable performance attributes (for example, producing a strong, cohesive ash) during the smoking period". ${ }^{18}$

The second segment (region E, $\sim 30 \mathrm{~mm}$, which we have highlighted in the figure by adding a narrow piece of dark paper), is an aerosol generating chamber and consists of shredded reconstituted tobacco which contains more than $50 \%$ glycerin. Aluminium foil (item F) lines the white cigarette wrapping and is used to conserve and direct the heated aerosol as it passes downstream.

The third segment $(\sim 40 \mathrm{~mm})$ consists of two components. The first component (item $G$, $\sim 30 \mathrm{~mm}$; we have denoted this region by adding a piece of light paper), is the second of the two tobacco chambers, and contains blended tobacco. The tobacco in this compartment delivers tobacco flavour and nicotine to the heated aerosol. The second component ( $\sim 10 \mathrm{~mm}$; item J) houses the filter. The filter, like that of conventional cigarettes, consists of a bundle of cellulose acetate fibres The Eclipse filter plug $(10 \mathrm{~mm})$ is considerably shorter than the filter plug $(20 \mathrm{~mm})$ of a standard filter cigarette. ${ }^{19}$ The conventional filter plug often begins at the designer rings (item $\mathrm{H}$ ). Thus the position of the rings on the Eclipse cigarette provides the smoker with an illusion of a longer filter. 
Eclipse also features a band of side ventilation holes (item I) that are employed to dilute the air, thus reducing the tar, nicotine, and carbon monoxide content of the inhaled tobacco-flavoured aerosol. ${ }^{19}$ Noteworthy, however, is the fact that the air vents of the Eclipse cigarette are positioned remarkably close to the end of the mouthpiece where they are likely to be blocked by the fingers or lips of the smoker. The positioning of the ventilation holes has been recognised as an industry ploy to deliver more nicotine and tar to the smoker than is recorded with the use of the current Federal Trade Commission testing method employed by the cigarette manufacturers. ${ }^{20}$

By eliminating the burning (pyrolysis) of tobacco, numerous components of the smoke are greatly reduced, including chemicals in both the particulate phase (for example, tar) and the vapour phase of cigarette smoke. When compared to a standard filter cigarette, RJR states that Eclipse provides a significant reduction in both benzo( $\alpha$ ) pyrene $(9.2$ to $0.1 \mathrm{ng})$ and nitrosamine (101 to $2.6 \mathrm{ng}$ ). ${ }^{1}$

Nicotine levels in Eclipse approximate those of a standard ultralight cigarette. ${ }^{1}$ In this regard, it is noteworthy that a US patent ${ }^{6}$ has been awarded for a non-pyrolytic cigarette, defined as a "nicotine dispensing device", which was developed to eliminate the disadvantages associated with conventional smoking of combustible cigarettes and which embodies features common to the Eclipse cigarette.

RJR states in a 1991 patent awarded for an Eclipse-like smoking article" that "spray dried tobacco extract" and "tobacco extracts" can be added to the product. This and other patents imply that the nicotine content and delivery can be adjusted to achieve a desired dose of the addictive drug.

Particularly alarming is the fact that the Eclipse cigarette delivers approximately the same amount of carbon monoxide as a standard cigarette. ${ }^{1}$ Carbon monoxide is a known poison, and is suspected of contributing to smoking related diseases, particularly cardiovascular diseases. ${ }^{21}$

The Eclipse cigarette is not consumed during smoking. Thus it is not surprising that difficulty has been encountered in determining when the cigarette is spent. Moreover, smokers in the test panels noted that extinguishing the Eclipse was difficult. As noted above, the heat from the fuel source of Eclipse (approximately $900^{\circ} \mathrm{C}$ ) approximates the fire cone of a conventional cigarette. ${ }^{15,19}$ For these reasons, an Eclipse cigarette with a burning charcoal fuel element may pose an even greater fire hazard than conventional cigarettes, resulting in more casualties and greater property losses. (However, the Chairman and CEO of RJ Reynolds made this claim about Premier: "When it is lit and lying flat, the cigarette is also unlikely to ignite most materials - a positive step in addressing the fire safety issue regarding the careless use of cigarettes."22)

Eclipse cigarettes generate little or no ash. The spent rods (figure: upper panel, middle cigarette) remain intact. If improperly dis- carded, the Eclipse cigarettes will invariably be an even greater source of environmental pollution than the myriad of cigarette butts that now litter our streets and beaches. ${ }^{23}$

The use of glass fibres as an insulating material may pose an additional health hazard. In a patent assigned to Philip Morris, ${ }^{10}$ Serrano et al note, in reference to a patent for an Eclipse-like cigarette assigned to Banerjee $e t$ al of RJR, ${ }^{5}$ that a resilient glass fibre insulating jacket is difficult to handle on modern mass production cigarette making machinery without special equipment. Moreover, "the glass fibres may become dislodged during shipping and migrate through the pack to rest on the mouth end of the article, giving rise to the potential for the inhalation of glass fibres into the smoker's mouth." The health hazards of the glass fibres have been addressed by RJR, which acknowledges studies in which glass fibres have been shown to induce pleural mesotheliomas in experiments of laboratory animals. ${ }^{15}$

RJR was sued recently by Schuller International Inc, a unit of the Manville Corporation, to bar its glass fibres from being used in "the manufacture of a new cigarette product for sale to the public". ${ }^{24}$ In the summer of 1993, RJR asked Schuller International Inc to supply between 20000 and 50000 pounds of glass fibre to RJR by December 1993. On 3 February 1994, RJR told Schuller the project had been delayed to work out the taste and aroma problems with the proposed new cigarette design.

Schuller claimed that the fibres were to be used in RJR's pilot operations and development efforts, and that none of the glass fibres were to be used in the commercial sale of cigarettes. Arguments were also presented regarding indemnification of Schuller by RJR, which related to a proposed draft agreement for the sale of glass fibres that "... defend, indemnify and hold harmless [RJR] ... against all claims, damages, losses and expenses... attributable to (a) bodily injury, or death, or (b) injury to or destruction of tangible property..."

In this suit, Schuller was asking the court for a jury trial and (a) sought to show that Schuller and RJR did not reach a meeting of the minds such than an enforceable contract was retracted, and (b) requested an award to cover attorney fees and costs and all other relief that may seem appropriate. Schuller, however, withdrew the case on 5 May 1995 after reaching a settlement with $R J R .^{25}$

Also relevant to this case is an excellent synopsis of the mechanisms of fibre induced diseases and the role of biopersistence in the pathogenicity of manmade fibres that has recently been presented by Thomas $H$ Hesterberg of Schuller International Inc and Roger O McClellan of the Chemical Industry Institute of Toxicology. ${ }^{26}$

\section{Discussion}

Eclipse is a technologically sophisticated smoking article, and is more costly to manufacture

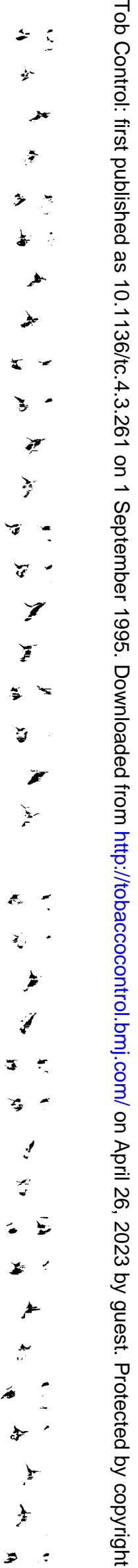

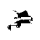


than conventional cigarettes being marketed today. This financial burden, as was the case with the Premier cigarettes, will be imposed upon the nicotine addicted smoker who, unable to quit and aware of the obvious health risks, may seek these new smoking articles because they may be perceived as safer than conventional cigarettes (see Perla et al, this issue, p 295).

The issue of perception also raises the question as to whether youngsters will be mislead to believe that a low-smoke cigarette is safe. This erroneous assumption may be used to challenge the advice of their parents, teachers, and health advisors. The end result could be a lifelong and costly addiction; whether the addictive drug nicotine is delivered in the form of a low-smoke or regular cigarette may prove irrelevant.

Noteworthy is that the Batelle Laboratories of Richland, Washington have been contracted by RJR to serve as an "independent" laboratory. Eclipse cigarettes, however, are not being made available to other groups for evaluation.

The evaluation of the Eclipse cigarette by different test panels has been terminated. Members of the panels found the Eclipse cigarette to be harder to draw than conventional filter cigarettes. In addition, difficulty was encountered in lighting the Eclipse cigarette. Response to the flavour and overall acceptability of the cigarette has been varied: individual responses have ranged from favourable to unacceptable.

Whether the low-smoke Eclipse cigarette will gain consumer acceptance remains to be determined, and RJR refuses to discuss future activities for this or related smoking devices.

To address health issues relating to carbon monoxide from the carbon fuel element, RJR has developed a tobacco smoking article with an electrochemical heat source. ${ }^{12,27}$

Philip Morris Inc have patented a cigarette similar to Eclipse, ${ }^{10}$ and they have also developed a cigarette that contains an electric heater for producing a flavour generated aerosol that contains very little carbon monoxide. ${ }^{8}$

\section{CONCLUSIONS}

Numerous patents that have been approved during the last few years document the intention of the tobacco industry to market new smoking articles. This new generation of technically sophisticated cigarettes and cigarette substitutes differs significantly from those currently being marketed. Many investigators and informed smokers believe that low-smoke prototypes are simply nicotine delivery devices.

If the US Food and Drug Administration is allowed to treat nicotine in tobacco products as a drug, it is conceivable that the manufacturers of these new smoking articles could be required to disclose to consumers information about their health risks. Up to now, cigarette manufactures have been free to distribute these products without regulation by the government.

All tobacco products, particularly devices that are being introduced to the market to mimic existing cigarettes, should be required to comply with regulations that have been enacted and enforced for many years to ensure the safety and efficacy of foods, drugs, and cosmetics.

The authors thank Dr John Slade for his critical review of the manuscript.

1 Hilts PJ. Little smoke, little tar, but still lots of nicotine New York Times, 1994 Nov 27: pp 1 and 38.

2 Solomon S, Cattiness J. Eclipsing the Premier. The Business Weekly. News and Record, Greensboro, North Carolina. Dec 12, 1994: pp 1, 8, 9.

3 Solomon S. Lab hamsters sample new Eclipse cigarette. The Business Weekly. News and Record, Greensboro, North Carolina. Dec 12, 1994: p 11.

4 US Patent 2,907,686. Siegel HI. Cigarette substitute and method. Oct 6, 1959 .

5 US Patent 4,714,082. Banerjee CK, Farrier EG, Reynolds $\mathrm{JH}$, et al. RJ Reynolds Tobacco Co. Smoking article. Dec $22,1987$.

6 US Patent 4,813,437. Ray JP. Nicotine dispensing device and method for the manufacture thereof. Mar 21, 1989.

7 US Patent 5,020,548. Farrier EG, Harris JL, Norman AB et al. RJ Reynolds Tobacco Co. Smoking article with improved fuel element. June 4, 1991.

8 US Patent 5,322,075. Deevi SC, Hajaligol MR, Herman $H$, et al. Philip Morris, Inc. Heater for an electric flavorgenerating article. June 21, 1994.

9 US Patent 5,327,915. Porenski H, Plotner RR. Brown \& Williamson Tobacco Co. Smoking article. July 12, 1994.

10 US Patent 5,345,951. Serrano MA, Houghton KS, Lanzillotti HV, et al. Philip Morris Inc. Smoking article. Sep 13, 1994

11 US Patent 5,345,955. Clearman JF, Meiring RL, Lawson JW, Baker KO. RJ Reynolds Tobacco Co. Composite fuel element for smoking articles. Sep 13, 1994.

12 US Patent 5,357,984. Farrier EG, Chiou JJ, Lehman RL. RJ Reynolds Tobacco Co. Method of forming an electrochemical heat source. Oct 25, 1994.

13 John GA. RJR has a Premier year. Tobacco International. Oct 15, 1989: pp 22-31.

14 deBethizy, JD et al. Chemical and biological studies of a cigarette that heats rather than burns tobacco. $f$ Clin Pharmacol 1990; 30: 755-63.

15 Chemical and biological studies of new cigarette prototypes that heat instead of burn tobacco. Winston-Salem: RJ Reynolds Tobacco Company, 1988 (744 pp).

16 Cuenot DA. The substitutes for tobacco. $\mathscr{F}$ Agric Trop Botan Appl 1967; 14: 192-252.

17 Anonymous. Consumer test of synthetic tobacco. Tobacco f Int 1974; 5: 309.

18 US Patent 5,220,930. Gentry JS. RJ Reynolds Tobacco Co Cigarette with wrapper having additive package. June 22, 1993.

19 Browne CL. The design of cigarettes. Charlotte, North Carolina: Hoechst Celanese, $1990(119 \mathrm{pp})$.

20 Kozlowski LT. Blocking the filter vents of cigarettes. f $A M A$ 1986; 256 : 3214 .

21 US Department of Health and Human Services. The health consequences of smoking: cardiovascular disease. A Report of the Surgeon General, 1983. Rockville, Maryland: Public Health Service, Office on Smoking and Health, 1983. Health Service, Office on Smoking and Ho
(DHHS Publication No (PHS) 84-50204.)

22 Horrigan EA. Statement at an RJR Nabisco press conference on Premier, New York City, 14 September 1987

23 Center for Marine Conservation. 1994 US national coastal cleanup results. Washington, DC: Center for Marine Conservation, June 1995.

24 Schuller International Inc, a Delaware Corporation (plaintiff) vs RJ Reynolds Tobacco Company, a New Jersey Corporation (defendant). United States District Court for the District of Colorado. Case No 95-S-535. March 6, 1995.

25 Manville unit settles suit naming RJ Reynolds Tobacco. Wall Street $\mathcal{F} 1995$ May 17.

26 McClellan RO, Hesterberg TW. Role of biopersistence in the pathogenicity of man-made fibers and methods for evaluating biopersistence: a summary of two round-table discussions. Environ Health Perspect 1994; 102(suppl 5) 277-83.

27 Davis RM, Slade J. Back to the future - with electrically powered cigarettes. Tobacco Control 1993; 2: 11-2. 